findings appeared in abstract form in the Scottish Medical fournal, January 1974.

Requests for reprints should be sent to $\mathrm{Dr} R \mathrm{M}$ Pearson.

\section{References}

${ }^{1}$ Leishman, A W D, and Sandler, G, Angiology, 1967, 18, 705.

2 Dorph, S, and Binder, C, Acta Medica Scandinavica, 1971, 185, 443.

${ }^{3}$ Motolese, M, Mulesan, G, and Columbi, A, European fournal of Pharmacology, 1975, 8, 21.

${ }^{4}$ George, C F, et al, Archives of Internal Medicine, 1972, 130, 361.

5 Bulpitt, C J, Dollery, C T, and Carne, S, Fournal of Chronic Diseases, 1974, 27, 309.

6 Jack, D B, and Reiss, W, fournal of Chromatography, 1974, 88, 173.

7 Armitage, P, Statistical Methods in Medical Research, p 226. Oxford, Blackwell Scientific, 1971.
8 Breckenridge, A, M, and Dollery, C T, Lancet, 1966, 1, 1074.

${ }^{9}$ Zacest, R, Gilmore, E, and Koch-Weser, J: New England fournal of Medicine, 1972, 286, 617

10 Sweet, C S, and Mandradjieff, M, Clinical Science, 1975, 48, 147.

11 Buhler, F, et al, American fournal of Cardiology, 1973, 32, 511.

12 Salvetti, A, et al, fournal of Nuclear Biology and Medicine, 1973, 17, 142.

${ }^{13}$ George, C F, in Biological Effects of Drugs in Relation to their Plasma Concentrations, ed D S Davies and B N C Prichard, p 128. London, Macmillan, 1973.

14 Cuthbert, M F, and Collins, R F, British fournal of Clinical Pharmacology, $1975,2,49$.

${ }^{15}$ Reiss, W, Huerzeler, H, and Raschdorf, F, Xenobiotica, 1974, 4, 365.

16 Brunner, C, Imhof, P, and Jack, D, European fournal of Clinical Pharmacology, 1975, 8, 3.

17 Leonetti, G, et al, Clinical Science, 1975, 48, 491.

18 Veterans Administration, Fournal of the American Medical As.ociation, 1967, 202, 1028.

\title{
Immunological mechanisms in the pathogenesis of vinyl chloride disease
}

\author{
A MILFORD WARD, SOPSAMORN UDNOON, J WATKINS, ANNE E WALKER, C S DARKE
}

British Medical fournal, 1976, 1, 936-938

\begin{abstract}
Summary
Vinyl chloride (VC) disease is a multisystem disorder incorporating Raynaud's phenomenon, acro-osteolysis, thrombocytopenia, portal fibrosis, and hepatic and pulmonary dysfunction. Immunological and immunochemical investigations showed the presence of circulating immune complexes in 19 out of 28 patients with the disease and in a further two out of 30 workers exposed to VC. The immunological data were reviewed in relation to the clinical picture of the disease and to the available evidence on the metabolism of VC. The results suggest that VC disease is an immune complex disorder and that the immune response is initiated by the adsorption of VC or a metabolite on to tissue or plasma protein.
\end{abstract}

\section{Introduction}

Vinyl chloride (VC) is known to be oncogenic, ${ }^{12}$ but hepatic angiosarcoma may not be the most serious of its medical hazards. Acro-osteolysis was first described in 1966 in workers employed in the polymerisation of $\mathrm{VC}^{3}$ and since then other cases have been described. ${ }^{5}$ In all these reports the affected workers helped in cleaning the autoclaves after the polymerisation process. Stewart et al, ${ }^{6}$ however, reported a case in a worker who had never done this job. Their report widened the possible exposure to toxic levels of VC to other workers in the industry. The descriptions of acro-osteolysis do not describe adequately

\footnotetext{
Protein Reference Unit, Department of Immunology, Hallamshire Hospital Medical School, Sheffield S10 2RX

A MILFORD WARD, MB, MRCPATH, director

SOPSAMORN UDNOON, BSC, research student

J WATKINS, BSC, PHD, principal scientific officer

Chesterfield Royal Hospital, Chesterfield

ANNE E WALKER, MD, MRCP, consultant dermatologist

Respiratory Function Unit, Royal Infirmary, Sheffield 6

C S DARKE, MD, FRCP, consultant
}

the full extent of the disorder as it may affect VC workers. The syndrome for which Lange et $a l^{7}$ suggested the name vinyl chloride disease includes sclerotic changes in the skin, osteolysis, circulatory disturbances, thrombocytopenia, portal fibrosis, and impaired hepatic and pulmonary function.

Despite considerable effort in many countries little is understood about the aetiology and pathogenesis of VC disease. We therefore outline the immunological investigations performed on 58 workers from a VC polymerisation plant. The results explain the pathogenetic mechanisms of the disease and allow some conclusions to be drawn about its aetiology.

\section{Patients}

The 58 patients were referred to a hospital clinic from a single VC polymerisation plant. They represented $18 \%$ of the past and present work force (320). Referrals of those still working at the plant were from either the factory medical officer or local general practitioners; ex-employees were referred after investigations made by the Employment Medical Advisory Service. For the purposes of the study the patients were divided into four clinical groups.

Group 1 ( 9 patients)-These patients were disabled by pain in limbs and hands and by dyspnoea. All had symptomatic Raynaud's phenomenon, which in five was clinically demonstrable; the others had severely cold hands. Four had scleroedema of the hands or face, four a mild clawing deformity of the hands, and two mild radiological evidence of acro-osteolysis.

Group 2 (19 patients)-This group was moderately disabled and multisymptomatic, excessive fatigue, limb pain, and paraesthesiae being the most common complaints. Raynaud's phenomenon was symptomatic but never observed, although many patients were found to have cold hands or feet. Scleroedema-like changes of the face were evident in two patients. No radiological abnormalities were seen.

Group 3 (25 patients)-These patients were not disabled and were continuing in active employment. They presented with miscellaneous symptoms that were not confirmed by visible abnormalities or overt clinical signs.

Group 4 (5 patients)-This group was asymptomatic, the patients having been referred because of expressed concern or because they wished to seek other employment.

The patients' ages ranged from 23 to 59 years with a mean of 39.7 years. There was no significant difference between the groups. The duration of exposure to VC varied from six to 75 months with a mean of 39 months. As the degree of exposure varied with the job at the plant the patients were divided into high- and low-exposure groups, the former being workers in the reactor building and dry-bagging 
plant, and the latter maintenance fitters and warehousemen. Fifty of the patients $\left(86^{\circ}{ }_{0}\right)$ had at sometime worked in the reactor building or dry-bagging plant. Altogether 46 patients $(79 \%$ ) admitted to having suffered from VC narcosis on at least one occasion; the incidence of admitted narcosis tended to decrease with diminishing severity of the disease-group $1,100^{\circ}$; group $2,80^{\circ}$; group $3,76 \%$; group $4,60 \%$. The differences do not approach statistical significance.

\section{Methods}

Immunoglobulins were estimated by an automated immunoprecipitin technique. Complement was determined in fresh EDTA plasma, C3 and $\mathrm{C} 4$ being estimated by single radial immunodiffusion and conversion assessed by two-dimensional immunoelectrophoresis. Cryoprotein studies were performed on warm-separated citrated plasma, the cold aliquot being kept at $4^{\circ} \mathrm{C}$ for seven days before separation of the cryoprecipitate. Rheumatoid factor was determined by passive haemagglutination of sensitised cells, and the presence of antitissue antibodies by indirect immunofluorescence.

Lymphocyte transformation was assessed by a modification of the technique of Schellekens and Eijsvoogel. ${ }^{8}$ Lymphocytes were separated from heparinised whole blood by a Ficoll-based centrifugation method. 9 Duplicate culture tubes were set up containing culture medium, autologous plasma, and either $0.2 \mu \mathrm{g}$ purified phytohaemagglutinin (PHA) (Burroughs Welcome) or $2 \mu \mathrm{g}$ purified protein derivative of tuberculin (PPD). Control cultures were set up using lymphocytes from healthy donors. All cultures were incubated at $37^{\circ} \mathrm{C}$ for 72 hours (PHA) and 120 hours (PPD). Transformation was assessed by the incorporation of tritiated thymidine into active DNA synthesis. Similar cultures were set up with test lymphocytes supplemented with normal plasma and normal lymphocytes supplemented with test plasma to assess possible plasma inhibitory effects. Lymphocyte subpopulations were defined as spontaneous E-rosette-forming cells or $T$ cells ${ }^{10}$ and as membrane-fluorescent cells or $B$ cells. ${ }^{11}$ Absolute numbers of $T$ and $B$ cells were determined as a percentage of the total lymphocyte count. Biopsy specimens were snap-frozen and cryostat sections stained for $\operatorname{IgG}, \operatorname{IgA}$, and $\operatorname{IgM}, \mathrm{C} 3$ and $\mathrm{C4}$, and fibrinogen/fibrin by direct immunofluorescence.

\section{Results}

The major abnormalities observed were a polyclonal increase in one of the immunoglobulin classes, usually IgG; the presence of mixed cryoglobulins, including $\mathrm{IgG}, \mathrm{C} 3$, and fibrinogen; and in-vivo conversion of both $\mathrm{C} 4$ and $\mathrm{C} 3$. Table $\mathrm{I}$ shows the mean values and ranges of immunoglobulins, C3, C4, and lymphocytes for each clinical group together with the numbers of patients with cryoproteins and showing $\mathrm{C} 3$ conversion. The abnormalities were present in almost all cases in group 1, and showed a progressively decreasing incidence in the other groups. The presence of circulating immune complexes was inferred when there was evidence of mixed cryoglobulins, in-vivo conversion of complement, and depressed values for C3 or C4; the presence of immune complexes showed a close relationship with clinical grouping, with $88 \%, 58 \%, 8 \%$, and $0 \%$ respectively for the four groups. Eight of the 58 patients were classified as of low exposure, six of them being in group 2 . No abnormalities were detected in these six patients. When the low-exposure workers are removed the incidence of circulating immune complexes in group $2(85 \%)$ closely approximates that in group 1.

Autoantibody screening (table II) showed no abnormalities except for a high incidence of antinuclear antibodies in group 1 . These were all of low titre (IgG 1/20-1/50) and probably resulted from tissue damage rather than an autoaggressive disease process. The only other observation of note was the presence of thyroid autoantibodies in three patients in group 2 .

There was evidence of a reduction in the $T$ cell population with a slight increase in B cells; this was most pronounced in group 1 but was also evident in group 2 and to a less extent in group 3. In-vitro stimulation showed few abnormalities except for an apparently increased frequency of reduced or absent responses to PPD. PHA transformation studies showed minor degrees of suppression, and inhibition by plasma was not seen.

Direct immunofluorescence studies of biopsy specimens of skin (10 cases), muscle (one case), and lung (one case) showed aggregates of IgG, C4, C3, and fibrinogen/fibrin in the lumen of vessels and adherent to the vascular endothelium. IgG, C4, C3, and fibrin were also detected in the media and subintimal regions of small and medium-sized arterioles.

\section{Discussion}

The major immunological features of VC disease in this series are hyperimmunoglobulinaemia, cryoglobulinaemia and cryofibrinogenaemia, and in-vivo conversion of complement involving the classic activation pathway via $\mathrm{C} 4$ and $\mathrm{C} 3$. There was additional evidence of a cellular disturbance in the form of a reduced $T$ cell population and a modest increase in $B$ cells. The presence of non-organ-specific antitissue antibodies in those most severely affected clinically may have related to tissue damage rather than to a pathogenetic mechanism.

Immunofluorescence studies of the biopsy material confirmed the immunochemical evidence of circulating immune complexes with the identification of immunoglobulin, complement, and fibrin/fibrinogen in the lumen of vessels, adherent to endothelium, and in the vessel wall. An immune complex or cryoglobulinaemic vasculitis would be consistent with the findings of a perivascular inflammatory infiltrate as described by Markowitz

TABLE I-Mean values and ranges for immunoglobulins, complement, and lymphocytes in tach group and numbers of patients in each group with cryoproteins and showing C3 conversions

\begin{tabular}{|c|c|c|c|c|c|c|c|c|c|c|c|c|}
\hline \multirow{2}{*}{ Group } & \multirow{2}{*}{$\begin{array}{c}\text { No of } \\
\text { patients }\end{array}$} & \multicolumn{3}{|c|}{ Immunoglobulins $(\mathrm{g} / \mathrm{l})$} & \multirow{2}{*}{ 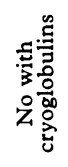 } & \multirow{2}{*}{ 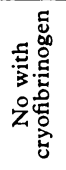 } & \multicolumn{2}{|c|}{ Complement $(\mathrm{g} / \mathrm{l})$} & \multirow{2}{*}{ 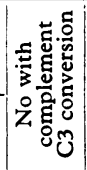 } & \multicolumn{3}{|c|}{ Lymphocytes $\times 10^{\circ} / 1$} \\
\hline & & IgG & IgA & IgM & & & C3 & C4 & & Total & $\mathrm{T}$ cells & B cells \\
\hline $\begin{array}{l}1 \\
2 \\
3 \\
4\end{array}$ & $\begin{array}{r}9 \\
19 \\
25 \\
5\end{array}$ & $\begin{array}{r}14 \cdot 3(10 \cdot 0-19 \cdot 0) \\
11.9(8 \cdot 3-18 \cdot 5) \\
9 \cdot 5(6 \cdot 8-11 \cdot 4) \\
12 \cdot 1(9 \cdot 5-16 \cdot 0)\end{array}$ & $\begin{array}{c}2 \cdot 8(1 \cdot 8-4 \cdot 7) \\
2 \cdot 4(0 \cdot 6-5 \cdot 0) \\
2 \cdot 0(0 \cdot 9-4 \cdot 1) \\
3 \cdot 6(1 \cdot 1-5 \cdot 2)\end{array}$ & $\begin{array}{l}1.3(0.4-2.7) \\
0.9(0.3-2 \cdot 1) \\
0.9(0.4-1.9) \\
1.0(0.5-1.4)\end{array}$ & $\begin{array}{r}8 \\
13 \\
2\end{array}$ & $\begin{array}{r}5 \\
13 \\
1\end{array}$ & $\begin{array}{l}1.0(0.6-1.5) \\
0.8(0.6-1.3) \\
0.8(0.5-1.2) \\
0.8(0.6-1.0)\end{array}$ & $\begin{array}{l}0.45(0.19-1 \cdot 10) \\
0.38(0.22-0.7) \\
0.45(0.32-0.69) \\
0.38(0.27-0.46)\end{array}$ & $\begin{array}{r}6 \\
9 \\
10 \\
3\end{array}$ & $\begin{array}{l}1 \cdot 8(1 \cdot 0-3 \cdot 1) \\
2 \cdot 4(1 \cdot 3-5 \cdot 4) \\
2 \cdot 0(0 \cdot 7-3 \cdot 0) \\
2 \cdot 5(2 \cdot 0-3 \cdot 0)\end{array}$ & $\begin{array}{l}0.4(0.1-1.5) \\
0.5(0.1-1.8) \\
0.4(0.1-1.0) \\
0.4(0.3-0.4)\end{array}$ & $\begin{array}{l}0.6(0.1-1.5) \\
0.7(0.3-1.5) \\
0.5(0.1-0.8) \\
0.5(0.3-0.6)\end{array}$ \\
\hline \multicolumn{2}{|c|}{ Normal values } & $9 \cdot 5(6 \cdot 0-14 \cdot 0)$ & $1 \cdot 8(0.5-3 \cdot 0)$ & $0.9(0.5-1.7)$ & & & $1 \cdot 2(0 \cdot 8-1 \cdot 7)$ & $0.45(0.30-0.75)$ & & $2 \cdot 0(1 \cdot 5-2 \cdot 5)$ & $1.0(0.6-1.5)$ & $0.7(0.4-1 \cdot 0)$ \\
\hline
\end{tabular}

TABLE II-Results of autoantibody screening in the four groups of patients

\begin{tabular}{|c|c|c|c|c|c|c|c|}
\hline \multirow{2}{*}{ Group } & \multirow{2}{*}{$\begin{array}{c}\text { No of } \\
\text { patients }\end{array}$} & \multirow{2}{*}{$\begin{array}{l}\text { No with } \\
\text { rheumatoid } \\
\text { factor }\end{array}$} & \multicolumn{5}{|c|}{ No with antitissue antibodies to: } \\
\hline & & & Nuclei (ANA) & Mitochondria (AMA) & Smooth muscle & Gastric parietal cells & Thyroid \\
\hline $\begin{array}{l}1 \\
2 \\
3 \\
4\end{array}$ & $\begin{array}{r}9 \\
19 \\
25 \\
5\end{array}$ & $\begin{array}{l}1 \\
1\end{array}$ & $\begin{array}{l}8 \\
2\end{array}$ & & $\begin{array}{l}2 \\
1 \\
1\end{array}$ & 1 & 3 \\
\hline Total & 58 & 2 & 10 & & 4 & 1 & 3 \\
\hline
\end{tabular}


et $a l, 5$ although the severe narrowing of dermal vessels with subintimal fibrosis described by Harris and Adams ${ }^{4}$ could be construed as an end-stage phenomenon of a similar process. Both histological features were present in this series, although the subintimal proliferation was seen only in the cases of longest duration. The tendency towards thrombocytopenia noted in many patients could be construed as confirmatory of an immune complex disorder with complement activation. ${ }^{12}$ The persistence of disease activity as evidenced by the presence of cryoprecipitate and conversion of complement in workers who had been removed from exposure to VC for more than six months is in accord with the observations of Veltman $e t$ al. ${ }^{13}$

Despite these pronounced abnormalities a search of published work on VC disease failed to disclose any similar investigation, most reports having concentrated on the hepatotoxic effects of VC and its oncogenic properties. Danishevsky and Egorev ${ }^{14}$ showed that tissue damage from VC could produce allergenic substances. Hervieux and Tessier ${ }^{15}$ had shown that a chemical dermatitis could be induced among workers in the industry. One patient in group 1 complained of skin irritation a year before, with evidence of Raynaud's phenomenon and dyspnoea, and gave a positive reaction to a patch test with polyvinyl chloride (PVC) powder. One other patient (group 3) had also complained of severe generalised pruritus.

In a detailed study of 13 patients employed in PVC production with circulatory disturbances, thrombocytopenia, splenomegaly, and hepatic malfunction, Lange $e t \mathrm{al}^{7}$ concluded that there was no evidence for an autoaggressive disorder. A more recent report $^{13}$ detailed the investigation of 70 patients from a work force of 128 at a single plant, the findings of which did not change the earlier conclusions. These workers did make the point, however, that although skin and bone changes may disappear when the patient is removed from contact with VC, the thrombocytopenia may persist for 12-18 months after exposure.

In a study of 36 workers exposed to $\mathrm{VC}$ who were shown to have leucopenia, thrombocytopenia, and splenomegaly, Suciu et $a l^{16}$ showed an increase in the $r$-globulin in 11 . Although they found only a $6^{\circ}{ }_{0}$ and $2 \cdot 9^{\circ}{ }_{0}$ incidence of clinical Raynaud's phenomenon in two series of VC workers, they noted that the phenomenon cleared spontaneously on removal from exposure and that the different incidence figures were associated with a 22 -fold decrease in VC levels. They also quoted a much higher $\left(66^{\circ}{ }^{\circ}\right.$ and $55^{\circ}{ }_{0}$, respectively) incidence of vasospastic changes in discussing the significance of the splenogmealy, they suggested that VC acted as an irritant in the reticuloendothelial system to produce a reactive splenic enlargement. Marsteller et al, ${ }^{17}$ in an extensive investigation of 50 VC workers, introduced some immunological tests into the initial protocol but abandoned them when they failed to give positive results. No comment was made on the presence or absence of hypergammaglobulinaemia. These workers also suggested the possibility of reticuloendothelial stimulation as a cause of the splenomegaly and the hepatic littoral cell hyperplasia, although they regarded the latter as a possible pathogenetic factor in the development of hepatic angiosarcoma.

The metabolism of VC in man is not fully understood. Hefner $e t$ al ${ }^{18}$ showed that in rats metabolism is by the alcohol dehydrogenase pathway at low concentration, and via an intermediate chloroethylene oxide at higher concentrations. Williamson $^{19}$ proposed that the intermediate product is more likely to be a cyclic dioxide. Both the oxide and dioxide would be highly reactive molecules and would be able to bind to free sulphydryl and amino radicals. The incorporation of these into protein synthesis would give a conformationally altered molecule that would be antigenic. The inclusion of this intermediate product with its chloride residue in a protein molecule would have a haptenic effect in the incitement of antibody synthesis. The theoretical interaction between VC and plasma proteins was partially confirmed by Oster ${ }^{20}$ in his observations of the binding of VC or its metabolite to serum albumin.

The association of the observed results with the experimental metabolic data allows the construction of a theoretical model for the pathogenesis of VC disease and explains many of the features of this multisystem disorder. A metabolic product of VC, presumably the dioxide, binds to plasma protein, producing either a haptenic group or a conformational change within the protein molecule. This acts as an antigen that escapes tolerance and stimulates $B$ cell proliferation and immunoglobulin production. The antibody and antigen interact to produce a soluble complex that is both cryoprecipitable and capable of initiating the complement sequence by the classic activation pathway. The cryoprecipitate and reactions secondary to complement activation will produce platelet aggregation and apparent thrombocytopenia, fibrinogen/fibrin conversion, and vascular occlusion. The vascular occlusion, either temporary or permanent, is enough to explain the observed clinical, radiological, and histological findings in the skin, skeletal and soft tissues, and lungs. By producing ischaemia the vascular occlusion would also stimulate new collagen biosynthesis, as observed by Jayson et al. ${ }^{21}$ This final episode in the pathogenesis of the disease process would then be further augmented by the interaction of collagen and complement, ${ }^{2: 2}{ }^{23}$ resulting in further activation of the complement pathway and thus reinforcing the terminal recycling phenomenon.

The frequency with which abnormalities were detected in exposed workers in this series, especially in those groups $(2$ and 3 ) in which there were few or no overt clinical signs, suggests that the disease process may be more common than is generally supposed. Further studies are in progress to investigate the total exposed population at the factory and to study populations from other related industrial plants.

\section{References}

${ }^{1}$ Lancet, 1974, 1, 1323.

2 British Medical fournal, 1974, 1, 590.

${ }^{3}$ Cordier, J M, et al, Cahiers de Médecine, 1966, 4, 3.

${ }^{4}$ Harris, D K, and Adams, W G F, British Medical fournal, 1967, 3, 712.

${ }^{5}$ Markowitz, S S, et al, Archives of Dermatology, 1972, 106, 219.

Stewart, J D, Williams, D M J, and McLachlan, M S F, fournal of Social and Occupational Medicine, 1975, 25, 103.

'Lange, C E, et al, Internationales Archiv für Arbeitzmedizin, 1974, 32, 1. Schellekens, P T A, and Eijsvoogel, V P, Clinical and Experimental Immunology, 1968, 3, 571.

Boyum, A, Scandinavian fournal of Clinical and Laboratory Investigation, 1968, 21, suppl No 97, p 9.

1" Steel, C M, Evans, J, and Smith, M A, British fournal of Haematology, 1974, 28, 245.

${ }^{11}$ Papamichail, M, Brown, J C, and Holborow, E J, Lancet, 1971, 2, 850

12 Pfueller, S L, and Lüscher, E F, Immunochemistry, 1972, 9, 1151.

${ }^{13}$ Veltman, G, et al, Annals of the New York Academy of Sciences, 1975, 246, 6

${ }^{14}$ Danishevsky, S L, and Egorev, N M, Gigiena Truda i Professional' nȳe Zabolevaniya, 1961, No 9, p 26.

15 Hervieux and Tessier, Archives des Maladies Professionnelles, de Médecine du Travail et de Sécurité Sociale, 1959, 20, 61.

${ }^{16}$ Suciu, I, et al, Annals of the New York Academy of Sciences, 1975, 246, 53.

17 Marsteller, H J, et al, Annals of the New York Academy of Sciences, 1975, 246, 95.

18 Hefner, R E, Watanabe, P G, and Gehring, P J, Annals of the New York Academy of Sciences, 1975, 246, 135

19 Williamson, K, Proceedings of the Royal Society of Medicine, 1976, 69, 281.

20 Oster, G, Annals of the New York Academy of Sciences, 1975, 246, 149.

21 Jayson, M I V, Bailey, A J, and Lloyd-Jones, K, Proceedings of the Royal Society of Medicine, 1976, 69, 295.

${ }^{22}$ Jobin, F, and Tremblay, F, Thrombosis et Diathesis Haemorrhagica, 1969, 22, 450 .

${ }^{23}$ Takahashi, M, Kawachi-Takahashi, S, and Matsuura, M, International Archives of Allergy and Applied Immunology, 1975, 48, 642. 